\title{
Life outside academia: on becoming an expert teacher-researcher
}

DOI 10.1515/ijtr-2015-0003

received January 15, 2015; accepted April 9, 2015

\begin{abstract}
The author, a school principal with significant classroom responsibilities recounts his journey towards authenticity as an independent teacher-researcher. His career as a researcher began in the scientific-knowledge tradition and then moved into the practical-knowledge tradition. He describes how Donald Schön, the father of reflective practice, has transformed his professional life, leading him to develop a deeply thoughtful practice, one that makes use of the literature to augment, challenge, and legitimise the work he does in his school. The author delves into the messy world of the professional experiment, and the idea that professionals can, and do, act and think differently to third-person researchers. Finally, the author shares his story about how the members of a virtual community of scholars have facilitated his move from the periphery of the researching community into an authentic and valued practitioner-colleague with a personal theory of practice.
\end{abstract}

Keywords: Donald Schön; reflective practice; practicalknowledge; professional practice; expert teacher

\section{Introduction}

One of the advantages of writing for the International Journal for Transformative Research is that it is possible to engage in an interactive and iterative process of review with a member of the editorial team. My reviewer is Dr. Joan Walton, of Liverpool Hope University in the United Kingdom. In the course of writing this paper, I have been challenged by Joan and educated by her too. As a consequence of our interaction, the final draft of the present

*Corresponding author: Peter Farrell, farrell.peter.pa@edumail.vic. gov.au paper has advanced my own theory of practice much further than I anticipated (in fact I did not know I had one). In particular, Joan has challenged my stereotyping of all academics with the same 'third-person methodology' brush. She has directed my attention to the real possibilities of second-person research to bring together theory and practice in the classroom.

My own view is this: I think expert-teachers should be engaged in solving problems of practice, and situating themselves within their own research and the literature. This may come from a wide range of sources, including personal communications, blogs, forums, magazine articles or peer-reviewed journals. The problems of practice that expert-teachers investigate should be contextual rather than theoretical and, I would argue, should deal with matters in the practical-knowledge tradition where the research output is for teachers and teaching rather than about them (Reid and Green, 2009). Contextual problems of practice are those identified by the individual or organisation in situ whereas theoretical problems arise from the themes, gaps and conundrums found in the research literature (Farrell, 2015).

Expert-teachers have pre-existing knowledge, skills, experience, values and their own theories of practice, and should use these first when addressing an issue; (they do anyway, so let's just acknowledge, legitimise and value that process). This is what Donald Schön (1987) identifies in professionals as the ability to think on one's feet. To ensure that the exercise is more than mere problem-solving, teacher-researchers should reflect on the matter after the event, and not just once but twice; the first reflection is little more than a review of the process and the result, and may identify the headlines arising from the investigation; whereas the second reflection, taking place much later, goes far deeper. This deeper process may make use of the literature (Farrell, 2012), a coach (Schön, 1987), critical friends (Samaras and Roberts, 2011), or a collaborative support group (Pithouse, Mitchell and Weber, 2009), where it is noted that the nature and make-up of the support group will influence the type and intensity of the interaction (Ovens and Tinning, 2009) and what is, and is 
not, acceptable in that community of practice (Lave and Wenger, 1991).

\section{A story}

Personal narrative writing is one of the creative approaches to self-study that we have used to engage groups of pre-service and practising teachers in a process of reviewing their educational experiences and practices and imagining new possibilities for authoring their own professional development (Pithouse et al., 2009, p. 49).

My interest in the practical-knowledge tradition began about 15 years ago when, at the age of 39, I found myself on a fish farm in North East of Victoria, Australia, completing a master's degree by research into the commercial production of a native freshwater crayfish. The work was very hands-on, and was driven by a desire to help farmers manage their husbandry better, but almost from the very beginning, there was a tension between my desire to find answers to the farmer's questions and what my supervisor wanted from me. Quite rightly, he wanted me to develop a well-argued, critically evaluated, theoretical stance. In response, I found myself spending more time in the library reading papers looking for themes, gaps and conundrums in the literature, so that I would be able to write about crayfish farming rather than for crayfish farmers, than where I would have preferred to be; on the farm. It is noteworthy that the research was initially pitched at PhD level but after about nine months, I did not think, at least while I was responsible for it, that the work would ever achieve the theoretical standard required. A research masters degree seemed a much better fit and I downgraded my candidature. I can only wonder now, if I had been working within a university setting, whether I would have been more inclined to persevere with the more academically demanding PhD. My supervisor and I did publish three peer-reviewed papers in the Journal of Applied Aquaculture; two of these were of direct interest to farmers (but none are relevant to the present paper).

For a variety of reasons, not pertinent to our discussion here, I eventually qualified as a generalist teacher and I began work in a small rural primary school. As I grappled with my new professional identity as a teacher, once again I found myself drawn to solving problems of practice in a practical, rather than a theoretical, way. This attitude was to continue after I took up the position of principal. At the time I had no idea that a practical-knowledge tradition even existed, my training and experience up to that point had been posited in the scientific-knowledge paradigm, albeit uncomfortably.

What then is practical-knowledge and why does it matter to teachers in particular? Guzman (2009) discusses the subject at length and created a four-quadrant taxonomy comprised of practice versus knowledge, and explicit versus tacit features, resulting in explicit and tacit practice, and explicit and tacit knowledge. In creating the taxonomy, Guzman (2009) pointed out that practical knowledge is situated, regulated, personal, relational and semantic. Practical knowledge generation is a social process mediated simultaneously by human agency and social structures. Unlike many other disciplines, teaching is quite young, and universities have only recently taken control of the generation and disbursement of authenticated science-based professional knowledge (Green, 2009). As a consequence, there is a dis-connect between teachers and education researchers and even hostility (Burns, 1999; Ekaz, 2006; Green, 2009). Practical knowledge is knowledge for teachers and teaching rather than about them and it.

It was about a year later that I discovered that La Trobe University, in Victoria, Australia, offered education doctorates (EdD). This seemed to be an eminently sensible way to continue my education at the time. The most attractive thing about the EdD approach for me was that it mixed coursework and research together, and the fact I could address an issue of professional rather than theoretical interest. This was particularly important as I intended to remain a school principal after I had completed the degree. After five-years of part-time off-campus scholarship I had written another thesis, this time about how school leaders with a significant teaching load, and those with an entirely administrative role, fostered culture in their schools. Once again, I had carried out a substantial study, while barely embedded in an academic environment. As was expected I did publish work from my thesis. These were a mix of peer-reviewed papers and magazine articles; but as I was remaining within my profession, I did not feel any pressure to publish my work in prestigious journals (where they would be hidden behind a subscription barrier). The e-journal I chose to publish in, Personal Construct Theory and Psychology, was dedicated to my research methodology, and was freely available to all (the content of those papers are not relevant to the present paper). My magazine of choice was a professional magazine directed at primary school principals in Australia. I also took some time to reflect on my experience in a personal memo to myself (Farrell, 2009), to differentiate between achieving the professional learning goals 
required for a practitioner-researcher and the academic learning outcomes required for a $\mathrm{PhD}$. Glasser (2013) identifies the personal memo as an important artefact in the research carried out by investigators working in the classic grounded theory tradition. In my memo my first idea was that the research question for an EdD should come from a problem of practice rather than from the gaps and conundrums in the literature. The second point I made was that one's research paradigm was of little importance and a more pragmatic stance was required of a practitioner-researcher, where I noted that problems were contextual rather than theoretical. Joan, my reviewer, was quite concerned about my stance:

There is so much to respond to in this one short sentence. Firstly, the choice of research paradigm is hugely important, wherever you are coming from in terms of research! It impacts enormously on all aspects of the research - the danger is, it is so often taken for granted and not spelt out, often leading to flawed research findings (Walton, 2015. pers. comm).

My third point was that practitioner-researchers completing an EdD focussed on school leadership should be investigating problems of practice around curriculum; data; finance; infrastructure; planning; resource provision safety, security and welfare; stakeholder relations, students, staff, and/or teaching and instruction. Each of these would be the subject of a small paper (chapter) and then a concluding, reflective chapter, would be written to pull the threads together and link in with the literature; it would become a professional research portfolio. I think this is where my thinking about school-related research began to move away from the orthodoxy of the $\mathrm{PhD}$ model to something a little more practical and flexible. I arrived at this way of thinking, I believe, because nearly all of my research experience had taken place off-campus, and outside the 'normative' culture of a university campus.

So what is meant by normative culture? Lave and Wenger (1991) discuss communities of practice and the concept of legitimate peripheral participation, and the socialising effect this has on the novice as they gravitate towards the attitudes, values and practices of the experienced 'old-timer'. My interpretation of this is that I was already working within the normative culture of the professional teacher. I was only ever on the periphery of the academic community, and never moved into the centre of that group. Subsequently, the socialising activities, the shared values, and the commonly accepted ways of being an academic were never offered to, nor embraced by me. In fact, I would argue the way of being an expert teacher was accepted, with a focus on solving problems of practice in a contextually, as opposed to a theoretically relevant way, reflected my professional practice.

This led me to investigate the whole area of professional learning and to discover a leading thinker in the field, Donald Schön. I purchased 'Educating the Reflective Practitioner' (Schön, 1987); reading this book transformed my professional life around reflective practice and how I would conduct school-based experiments. Schön's (1987) describes three types of professional experiments and these are, move-testing, exploratory and hypothesis testing. A move-testing experiment is set up with a desired outcome in mind, and one either gets the desired result, or one does not. An exploratory experiment is run with no pre-defined outcome in mind. Schön's (1987) third approach, hypothesis testing, would appear to be similar to a science-based experiment, but is not. Unlike scientific research, the professional researcher will manipulate the variables to force a desired outcome.

In 2011, I was undertaking a post-graduate certificate course in primary mathematics teaching. The course was a combination of residential and on-line learning and there was a great deal of latitude given as to what we could investigate in our own classrooms and how we would report on it. I decided that this provided an opportunity to test out my personal theory about how teacher-research could be done. The result of that work was what I described as a professional thesis where I investigated a problem of practice around the tutoring of my students as they worked their way through an on-line mathematics course. For my methodology I adopted the move-testing approach described earlier and thus, beginning with my own experience, knowledge, skill and values, I ignored the literature and started my investigation by gathering and describing the data I had. Consequently, I made a determination of where I believed each student's conceptual weakness lay. It was only after my own attempt to solve the issue that I consulted the 'literature'; I say literature, but there were only three refereed papers, an education department website, and two old textbooks (that I had in my own professional library). I then re-visited my data and re-analysed it for conceptual weaknesses in light of my new knowledge. I would name this step after Schön (1987) reflection-on-reflection-in-action in my thesis and this was my conclusion (Farrell, 2011, p. 31):

I conclude that Donald Schön reflection-on-reflection-in-action has much to commend it as a template for the 'professional' thesis written by an experienced practitioner. A professional thesis is different to the academic thesis in that the problem is set by the organisation and not from gaps and conundrums in the literature; it privileges professional knowing-in-action and accepts that the research problem may be messy. The rigor in the 
process of professional reflection comes from being prepared to accept that one may be right or wrong in one's initial thinking, and that by honest appraisal of one's practice against the appropriate literature, it is possible to add new content, ideas, values and skills to one's knowing-in-action; even if just incrementally.

While I was happy with what I had done, the fit between Schön and myself was not seamless. In his book (1987) he suggests the professional should make use of a coach to facilitate learning but I did not have one. I reflected on the matter in a personal memo (Farrell, 2012) and came up with a workable solution; instead of a coach I would use both professional and academic reading to augment, challenge and legitimise my practitioner knowledge, values and attitude.

In 2012 the state department of education proposed that teachers should be engaged in researching problems of practice in their own classrooms and invited submissions from interested people about the idea; of course I was interested! I eventually decided that my submission might be turned into a paper or magazine article, but to make the article suitable for publication I needed to learn more about researching problems of practice. I found, via Google: 'Understanding and Researching Professional Practice' edited by Bill Green (2009) and read each chapter closely, annotating the pages as I did so. In my paper (Farrell, 2013, p.35) I wrote:

Teachers may investigate any number of matters in their professional practice. They may have an untested or under-elaborated theory about something; they may just want to change the status quo; they may want to study the interaction between people, or to react to the provision of, or to the lack of resources in their workplace; they may investigate a pattern of work; and/ or challenge the assumption implicit in their own work. These are a broad range of issues and each may respond to a modest or quite extensive study depending on the context (italics used here for emphasis).

I took long service leave for the first term of the 2014 so I could just write and the outcome was four PDF books covering topics as diverse as leading a very small school, pedagogy in very small schools, a manual for teachers in positions of responsibility, and a review of the recently revised Australian national curriculum and how it might be delivered in a very small school like mine. The books were initially written for Amazon Kindle, but then I found Academia.edu, an on-line repository of free-access academic material. This seemed a much better fit for an independent researcher like myself, and so it proved to be. In it I could share my own work and read and correspond with other researchers with common interests to my own. This was to have quite unforeseen consequences.

Iranian academic, Associate Professor Mohommad Ali Salmani Nodoushan (2009) had noticed I had bookmarked a paper he had written about how teachers could conduct action-research following a science-based paradigm. We began an exchange of on-line messages resulting in my being invited to write about a move-testing experiment, around teaching grammar, I was conducting in my own school in the practical-knowledge tradition. Mohommad, as it turns out, was the editor of the International Journal of Language Studies. He helped me by providing references, editing and encouragement, to produce a substantial text of 10,000 words (Farrell, 2015). I was very pleased with this paper, and was mindful of the irony of making the case for professional research in the practical knowledge tradition in an academic journal.

In the process of researching the paper, I discovered a group of people on Academia.edu with an interest in the area of self-study research. While not exclusively so, it is an approach of great interest to reflective teachers and it seemed to be a good fit for me philosophically and pragmatically. I made contact with South African researcher, Dr. Kathleen Pithouse of KwaZulu-Natal University, and Dr. Alan Ovens of the University of Auckland in New Zealand, to learn that self-study is a broad-church. It is both eclectic and transformative, and it is neither stuck in time nor place (Pithouse et al., 2009). It is also a radical departure from more orthodox research paradigms and superficially at least, shares some common ground with classic grounded theory (CGT). This is an approach where the researcher deliberately avoids the development of any pre-conceived notions, ideas or theoretical frames of reference, allowing the theories to develop out of the data (Christiansen, 2011). The major point of difference is that my process is inward looking, and I am situated in the investigation. CGT looks outward and lets the data speak for itself.

To summarise, my theory of practice begins with a contextual problem of practice, followed by the collection and analysis of the data, and only then do I access the literature (like CGT) to legitimise, augment and challenge my professional practice (reflective practice). Following the pattern of self-study teacher research, I embed myself within my own experiments and act as an active agent. Despite my earlier dismissing of the importance of a research paradigm, I now find I have one. It is not set in stone, but is subject to continual revision in the light of new knowledge and understanding. 


\section{A reflection}

Walton and Harrison (in press) describe how first, second and third person research might be integrated. This is an idea I have only become aware of in the course of preparing this paper. Third-person research is the traditional science-based investigation, and one of the outputs from this kind of research is to publish the results of that study in a peer-reviewed journal. Walton and Harrison (in press) describe this approach as being about 'them'. In contrast, first-person research is grounded in practice and produces findings of personal interest to the researcher. Walton and Harrison (in press) discuss this as the 'I' in the research. Second-person research is the 'we' in research (Walton and Harrison (in press)) and I think it is the missing piece in my transformation to becoming an academic grounded in professional practice; or should that be, a professional grounded in academic scholarship? Walton and Harrison (in press) cite Reason and Bradley (2003, p.169-170) who say this:

[First] person inquiry is the foundation for all good action research; however, second person inquiry is the arena where the most energy and practical opportunity for really impacting practice occurs - while third person work is, finally, the most important, as it affects the conditions which ultimately shape the future context in which first and second work can occur. Keeping an eye to integrating the three modes, always being concerned with working in at least two modes is especially important (Reason and Bradley, 2003, p.169-170).

What is apparent to me now is that I am a person posited within first-person research trying to justify myself as a credible academic in the third-person paradigm. This is why I feel the tension of trying to straddle, what I hold to be, two different ways of knowing; science-based and practical knowledge. The present paper is an attempt to bridge the gap between these two forms of knowing, but what has been made apparent to me by my reviewer, is that I have too readily tried to find those points of difference between academics and professionals, rather than looking for those areas of common interest. In doing so, I have tarred all academics with the same third-person brush. One of the most exciting developments arising from writing this paper in an interactive way is that I have learnt about having a personal theory of practice which is, I think, less limiting than the practical-knowledge paradigm.

Joan, my reviewer, was concerned about my reflective process where I used the literature to legitimise, augment and challenge my knowledge:
In good quality research, you do not look to academic literature for support, whether at the beginning, middle and end of your own work. You should use it to help you to reflect critically on what you are doing or have done; indeed to actively look for literature or research which may challenge your own findings / experience. You then need to think what an informed response to that challenge might be. It is a process of this nature that will lead to 'rich' findings, which are not influenced by implicit assumptions. If you just look at literature for support, you are going to be inappropriately biased in terms of what you choose to read and report on (Walton, 2015, pers. comm.).

My response is that she is quite right, but I think there remains a distinction between science-based and practical-knowledge research, and it is worth discussing because it is a nuanced difference. First of all investigators in the practical-knowledge tradition will have a much broader definition of what is appropriate and acceptable literature including refereed papers (especially open access), magazine articles, text books, blogs, forums and personal communications. A second distinction between practical and academic researchers, is that the former are interested in having their practice legitimised by others. This is particularly true of teaching and teachers in my experience, where the 're-invention of the wheel' is a process to be avoided in Australian schools at least. In addition to legitimising professional knowledge, my process requires that I augment and challenge it too (Farrell, 2015) and this is in accordance with my reviewer's wishes. On reflection, I think second-person research as described by Walton and Harrison (in press) as the 'we' in research may provide an effective and acceptable research paradigm for linking theory and practice in schools and in universities. By engaging others in our research, there will be opportunities to legitimise, augment and challenge professional and academic ways of knowing.

In describing professional practice Schön (1987, p. 3) uses the metaphor of the high ground overlooking the swamp and suggests that on the high ground there are well-defined problems that can be solved using researchbased theory and the application of technical instruments whereas, 'In the swampy lowland, messy, confusing problems defy technical solutions (p.3)'. The theoretical challenge I do face is making the case for the way I do research acceptable to a critical reader. However, it is difficult to get away from practical concerns.

I think my first challenge is addressing how I go about intensifying the quality and range of those relationships I have with the academic world, and move from the periphery to the centre of this community (Lave and Wenger, 1991). In a magazine article, Samaras and Roberts (2011, p. 43) laid out the steps necessary to carry out self-study research beginning with: 1). Authoring your own question, 
2). Work with a critical friends team, 3). Plan new pedagogies for improved learning, 4). Enact, document and assess, and 5). Generate and share what you have learnt. Of all the steps Samaras and Roberts (2011, p. 43) describe, step 2 is the most problematical for me, as I am now quite used to independent scholarship. The method for reflection adopted by Ovens and Tinning (2009) involved writing in the third person about events from memory and discussing these as a group; I have never reflected in this way. Invariably, I write my reflections in the first person, and I always reflect alone, so perhaps it is time for me to identify 'fellow-travellers'? But who should they be? Do I need to find more than one group? Should the group be based upon particular interests, for example: small school leadership, teaching and learning in very small schools, teacher-research? Alternatively, going back to Donald Schön (1987), perhaps I should find a skilful coach to help me reflect. Schön (1987, p. 311) stated that the coach's ability depends on their artistry as a coach rather than skill as a lecturer or attainments as a scholar. The reflective process requires that the coach helps to surface the knowing-in-action of the student, whilst at the same time linking the student with appropriate and helpful researchbased theories.

The present paper covers 15 years of my professional life. A slow transformation some might say, but a deeply felt one. I have come to value reflective professional learning. What I have learnt since writing the present paper is that the context matters when teachers are engaged in reflective practice. Ovens and Tinning (2009) suggest that reflection be viewed as a situated activity set within a 'discourse' community. They observed that the type and quality of reflection changed, as the participants in their study moved between the community of the education student at the university, to the community of teachers and teaching in schools. In a sense this is going full-circle for me, because two of the earliest thinkers influencing how I fostered the learning culture in my school were Lave and Wenger (1991), who wrote a book about situated communities of practice. The interactions I have had on Academia.edu might qualify as such an arrangement. Those of us who use the forum are researchers from around the world, and we are at various stages of our careers. We each interact and learn together and, where we can, we try to help each other, to varying degrees. After an unorthodox start to my career as a researcher, either off-campus and-or part-time, I have found a virtual community with members who embrace self-study teacher-research with its focus on practical-knowledge, and the personal theory of practice.

\section{Conclusions}

As I look back over the text I realise how much of a role chance played in my evolution. Being off-campus and dealing with practical issues; then being part-time and holding down a responsible job unrelated to academia; taking on an EdD rather than a $\mathrm{PhD}$ and being a little disappointed about it; discovering Donald Schön and becoming a reflective practitioner, albeit one without a coach and in need of an alternative (the literature); discovering an on-line situated community of practice with insiders willing to support people on the periphery like myself and in the process, discovering self-study, a truly transformative (and legitimising) paradigm. I am not certain if Donald Schön ever really elaborated on how professional experimentation and reflective practice could be combined together, and I am not even sure he intended that they be linked together in the way I have, but it works for me, and that is all it has to do to be my theory of practice.

I want to conclude by saying I am not against third-person researchers, or their academic behaviour, but I do think that what they do, and what they want from their research is different to what I do, and what I want from mine. What I have come to understand in the course of writing the present paper is that there are fellow travellers out there and I think that all first-person researchers, be they working out of the classroom, or from the lecture hall, need to work together on matters of common interest; and we need instruments, people, and arrangements, like the interactive review process used by this journal, and second-person research methodologies, to facilitate that interaction.

\section{References}

[1] Burns, A. (1999). Collaborative action research for English language teachers. Cambridge University Press. Cambridge, UK

[2] Christiansen, Ó. (2011). The literature review in classic grounded theory studies: A methodological note. The Grounded Theory Review. 10 (3). Retrieved from: http:// groundedtheoryreview.com/2011/12/20/the-literature-reviewin-classic-grounded-theory-studies-a-methodological-note-2/

[3] Ekiz, D. (2006). Primary school teachers' attitudes towards educational research. Educational Sciences: Theory \& Practice 6(2), 395-402

[4] Farrell, P. (2015). Teacher-research and the art of the professional experiment: Reflective practice in the practicalknowledge tradition. International Journal of Language Studies, 9(1) 1-21

[5] Farrell, P. (2013). Teacher-researchers and the discovery and dissemination of professional practice. Australian Primary Mathematics Classroom, 18 (4) 34-37 
[6] Farrell, P. (2012). The use of professional reflection and professional reading to challenge, legitimize and augment practitioner knowledge, values and attitudes (A memo). https://www.academia.edu/7785311/ The_use_of_professional_reflection_and_professional_ reading_to_challenge_legitimize_and_augment_practitioner_ knowledge_values_and_attitudes.

[7] Farrell, P. (2011). Identifying Mathematical Misunderstanding in the Students and their Teacher. Postgraduate Certificate in Primary Mathematics Teaching Thesis, Faculty of Education, Royal Melbourne Institute of Technology University, Melbourne, Victoria. https://www.academia.edu/7785403/ Identifying_Mathematical_Misunderstanding_in_the_ Students_and_their_Teacher

[8] Farrell, P. (2009). Making a professional doctorate professional: Ideas for the future of the doctorate of education (A memo). https://www.academia.edu/6433601/Some_ thoughts_about_my_professional_doctorate

[9] Glasser, B. (2013), Introduction: Freestyle memoing. The Grounded Theory Review. 12 (2). Retrieved from: http://groundedtheoryreview.com/wp-content/uploads/2014/03/1202_01. pdf

[10] Green, B. (2009). Introduction: Understanding and researching professional practice. In B. Green (Ed.), Understanding and researching professional practice. (pp. 1-18). Sense Publishers, Rotterdam, The Netherlands
[11] Guzman, G. (2009). What is practical knowledge? The Journal of Knowledge Management 13(4): 86-98

[12] Lave, J. and Wenger, E. (1991). Situated Learning: Legitimate Peripheral Participation. Cambridge: Cambridge University Press

[13] Ovens, A., and Tinning, R. (2009) Reflection as situated practice: A memory-work study of lived experience in teacher education. Teaching and Teacher Education 25: 1125-1131

[14] Pithouse, K., Mitchell, C., and Weber, S. (2009) Self-study in teaching and teacher development: a call to action. Educational Action Research 17: (1) 43-62

[15] Reid, J., and Green, B. (2009) Researching (from) the standpoint of the practitioner. In B. Green (Eds.), Understanding and researching professional practice. (pp. 165-183). Sense Publishers, Rotterdam, The Netherlands

[16] Salmani Nodoushan, M. A. (2009) Improving learning and teaching through action research. The Modern Journal of Applied Linguistics, 1(4), 211-222

[17] Samaras, A., and Roberts, L. (2011) Flying solo: Teachers take charge of their learning through self-study research. JSD 32 (5) 42-45

[18] Schön, D. O (1987). Educating the Reflective Practitioner. Jossey-Bass higher education series: San Francisco, USA.

[19] Walton, J. \& Harrison, N. (2015) Integrating first, second and third person research to lead the creation of a learning organisation, in Pithouse-Morgan, K (ed) Polyvocal Professional Development: Enacting dialogic professional learning through self-study, Sense Publications. 